\title{
Crescimento do girassol sob sistema de captação de água "in situ” e adubação orgânica ${ }^{1}$ \\ Sunflower growth system funding under water "in situ" and organic fertilizers
}

\author{
José A. C. Wanderley ${ }^{2}$; Carlos A. V. de Azevedo ${ }^{3}$; Marcos Eric B. Brito ${ }^{4}$; Francisco Cássio G. Alvino ${ }^{5}$;José da \\ S.Sousa ${ }^{6}$
}

Resumo: A importância econômica do girassol é devido principalmente o óleo extraído de suas sementes, como também expressa potencialidade no uso forrageiro, podendo ser cultivado na região semiárida nordestina, onde se caracteriza pelas irregularidades das chuvas, todavia, o cultivo pode ser limitado pela baixa disponibilidade hídrica e adubação inadequada, nesse sentido, objetivou-se avaliar o crescimento do girassol cultivado sob sistema de captação de água e adubação orgânica. O experimento foi instalado em campo, da UFCG, Campus de Pombal, onde foram testado, em DBC, fatorial 4 x 5, sendo quatro sistemas de cultivo: camalhão, sulco, bacias e em plantio convencional combinadas a cinco níveis de esterco $\left(0-2,5-5-7,5\right.$ e $\left.10 \mathrm{~L} \mathrm{~m}^{-2}\right)$, em seis repetições. Aos $20,40,60$ e 80 dias após a semeadura, realizou-se avaliações : diâmetro de caule ao nível do solo, altura de planta, e número de folhas e, ao 84 DAS determinou-se a área foliar . No transcorrer do experimento foram realizadas irrigações suplementar as precipitações, com base na ETo. Constatou-se efeito combinado entre técnicas de captação de água e quantidades de esterco no crescimento do girassol. Plantas de girassol cultivadas na linha do camalhão e adubação com esterco bovino aumenta a área foliar.

Palavras-chave: Sulcos, camalhões, bacias e esterco.

\begin{abstract}
The economic importance of the sunflower is mainly due to the oil extracted from its seeds, but also expresses the potential forage use and can be cultivated in semi-arid northeastern region, which is characterized by irregularity of rainfall, however, the cultivation may be limited by low water availability and inadequate fertilization, accordingly, aimed to evaluate the growth of sunflower cultivated under water collection and organic fertilization system. The experiment was installed in the field, UFCG, Campus de Pombal, which were tested in DBC, 4 x 5 factorial, four cropping systems: ridge, groove, bowls and conventional tillage combined with five levels of manure ( 0 $2,5-5-7,5$ e $10 \mathrm{~L} \mathrm{~m}^{-2}$ ) in six replicates. At 20, 40, 60 and 80 days after sowing, evaluations were performed: stem diameter at soil, plant height level, and number of leaves and, at 84 DAS determined the leaf area. . Throughout the experiment supplemental irrigation precipitations were performed, based on ETo. It found a combined effect of water harvesting techniques and amounts of manure on growth of sunflower. Sunflower plants grown on the ridge line and the cattle manure increases the leaf area.
\end{abstract}

Key words: grooves, ridges, basins and manure.

\section{INTRODUÇÃO}

A cultura do girassol (Helianthus annuus L) se enquadra como importante fornecedora de matéria-prima para a produção de bicombustíveis (Freitas et al., 2012), demonstrando grande potencial de expansão devido, à diversidade de aplicações em diferentes áreas, como produção de ração, silagem, óleo para consumo humano, floricultura e alimentação animal, além de ser excelente alternativa de matéria-prima para a produção de biodiesel (RIGON et al., 2010).

De acordo com Santos Júnior et al., (2011) trata-se de uma cultura, de alto valor comercial, encontrando-se em evidência no mercado em virtude de seu potencial agronômico de aproveitamento de todas as partes da planta. É uma cultura que se adapta a diversas condições edafoclimáticas podendo ser cultivado no Brasil, desde o
Rio Grande do Sul até o hemisfério norte no estado de Roraima (GOMES et al., 2010).

Segundo Neumann et al., (2009) o girassol se configura entre as espécies com potencial forrageiro com maior tolerância ao estresse hídrico, destacando-se como cultura apropriada para esta situação, além de se caracterizar por apresentar maior tolerância de cultivo a baixas e altas temperaturas (entre $5^{\circ} \mathrm{C}$ e $40^{\circ} \mathrm{C}$ ), quando comparada com as demais espécies forrageiras, isto não significada afirmar que seu desenvolvimento não será alterado em condições de estresse hídrico (FREITAS et al., 2012). Existe um aumento na área agrícola explorada com o girassol no semiárido, o que tem despertado o interesse de pesquisadores em conhecer o comportamento relacionado ao crescimento e à produção desta cultura nas

\footnotetext{
*Autor para correspondência

Recebido para publicação em 20/11/2013; aprovado em 05/05/2014

1 Pesquisa financiada pelo CNPq e parte da Dissertação Mestrado apresentado ao Programa de Pós Graduação em Eng. Agrícola, UFCG

2 Eng. Agr. Doutorando em Engenharia Agrícola. Universidade Federal de Campina Grande, (UFCG), Campina Grande, PB. Rua Vicente de Paula

Leite, 352, CEP: 58840-00, Pombal-PB, Brasil. Tel.(83 ) 991239112, E-mail: alberto_agronomo@ hotmail.com

3Prof. Doutor, Unidade Acadêmica de Engenharia Agrícola, UFCG, Campina Grande, PB

4 Prof. Doutor, Unidade Acadêmica de Ciências Agrárias, UFCG, Pombal, PB

5 Eng. Agr, Centro de Ciências e Tecnologia Agroalimentar, UFCG, Pombal, PB

6 Eng. Agr. UFCG, Msc. Agronomia, UFPB, CCA, Areia,PB
}

Revista Verde (Mossoró - RN - Brasil), v 9. , n. 2 , p. 129 - 138, 2014 
condições edafoclimáticas da região (SANTOS JÚNIOR

No entanto, mediante as condições edafoclimáticas da região semiárida do Nordeste brasileiro, comumente afetada por um regime irregular das chuvas, em razão da insuficiência e da sua má distribuição ao longo dos anos. Segundo Oliveira et al., (2012), tal fato constitui um dos fatores mais limitantes às produtividades agrícolas, comprometendo significativamente o rendimento das culturas.

Acredita-se que, dentre essas alternativas, o sistema de captação de água in situ, que consiste na modificação da superfície do solo de modo que o terreno entre as fileiras de cultivo sirva de área de captação, viabilize a produção em áreas com limitação hídrica, notadamente em áreas que apresentam uma inclinação que intensifica o escoamento superficial, sendo que as técnicas podem proporcionar, ao mesmo tempo, o direcionamento da água para a porção do solo explorada pelo sistema radicular da planta (PORTO et al.,1990).

Estudos realizados por Laime (2012) e Bernal (2007), comprovam a eficiência dos sistemas de captação de água aumentando a conservação da umidade no solo, o que reflete no crescimento das culturas.

Aliado a essas técnicas, o uso de material orgânico pode favorecer a conservação da água, visto que, com o

\section{MATERIAL E MÉTODOS}

O experimento foi conduzido em condições de campo, entre os meses de abril e maio de 2012 no Centro de Ciências e Tecnologia Agroalimentar (CCTA) da Universidade Federal de Campina Grande, Campus de Pombal, Paraíba, PB, localizado sob as coordenadas geográficas de $6^{\circ} 48^{\prime} 16^{\prime \prime}$ de latitude $\mathrm{S}$ e $37^{\circ} 49^{\prime} 15^{\prime \prime}$ de longitude W e altitude de $144 \mathrm{~m}$. Segundo Köeppen, o et al., 2011).

uso frequente de resíduos orgânicos nas plantações, consegue-se, ao longo de alguns anos, melhoria na qualidade física do solo com aumento da água disponível, além de favorecer a diminuição na aplicação de adubos minerais melhorando a qualidade do solo e atuando como condicionadores (SILVA et al., 2008). De acordo com Oliveira et al., (2009) a aplicação de matéria orgânica ao solo contribui não só para o fornecimento de nutrientes mas também para a melhoria das características físicas do meio de cultivo, assim, o uso de matéria orgânica de forma equilibrada é de fundamental importância para o pleno desenvolvimento das plantas..

Uma das maneiras de identificar se os fatores abióticos que interferem nos processos vitais dos vegetais estão presentes adequadamente, é a quantificação das medidas de crescimento, pois, de acordo com Bennicasa et al., (2003), a análise de crescimento está relacionado com atividade fotossintética, pois, $90 \%$ da matéria seca acumulada ao longo do crescimento, é proveniente deste processo.

Deste modo, objetivou-se quantificar o crescimento do girassol cultivado sob técnicas de captação de água in situ e aducação com esterco bovino nosso.

clima predominante da região é do tipo BSh, ou seja, semiárido quente e seco, apresenta um período de chuvas irregulares entre os meses de fevereiro a junho, e um período de seca entre os meses de julho a janeiro com precipitação média de $750 \mathrm{~mm}$, e evapotranspiração média anual de $2000 \mathrm{~mm}$. O solo da área experimental é da classe dos aluviões, textura areia franca.

Tabela 1: Características químicas e físicas do solo utilizados nos diferentes tratamentos, Pombal, PB, 2012.

\begin{tabular}{|c|c|c|c|c|c|c|c|c|}
\hline C.E. & $\mathrm{pH}$ & $\bar{P}$ & $\overline{\mathrm{K}^{+}}$ & $\mathrm{Ca}^{-2}$ & $\mathrm{Mg}^{+2}$ & $\mathrm{Na}^{+}$ & $\overline{\mathrm{Al}^{3+}}$ & $\mathrm{H}^{+} \mathrm{Al}^{3+}$ \\
\hline $\mathrm{dS} \mathrm{m}^{-1}$ & $\mathrm{H}_{2} \mathrm{O}$ & $\mathrm{mg} \mathrm{dm}^{-3}$ & \multicolumn{6}{|c|}{$\mathrm{cmol}_{\mathrm{c}} \mathrm{dm}^{-3}$} \\
\hline 0,15 & 6,36 & 5,43 & 0,44 & 3,34 & 1,66 & 0,06 & 0,00 & 1,07 \\
\hline SB & CTC & \multirow[t]{2}{*}{$\bar{V}$} & PST & $\mathrm{N}$ & Areia & Silte & Argila & \multirow[b]{2}{*}{ Classe } \\
\hline \multicolumn{2}{|c|}{$\mathrm{cmol}_{\mathrm{c}} \mathrm{dm}^{-3}$} & & $\%$ & & & $\mathrm{~g} \mathrm{~kg}^{-1}$ & & \\
\hline 6,03 & 7,10 & 23,33 & 0,91 & 0,04 & 80 & 14,06 & 5,49 & Areia franca \\
\hline
\end{tabular}

O delineamento experimental foi em blocos ao caso, com tratamentos arranjados em esquema fatorial (4 $\mathrm{x}$ 5), com seis repetições, em que o primeiro fator se refere às técnicas de captação de água “in situ”, correspondendo aos camalhões (TC), sulcos (TS), bacias (TB) e plantio convencional (PC) correspondente a testemunha, no segundo fator estudou-se cinco níveis de esterco bovino $\left(0,0-2,5-5-7,5\right.$ e $\left.10 \mathrm{~L} \mathrm{~m}^{-2}\right)$, totalizando, assim, 120 parcelas experimentais, dotada de uma área de $6 \mathrm{~m}^{2}$. As parcelas foram formadas de seis linhas de $2 \mathrm{~m}$, sendo consideradas como área útil oito plantas centrais da parcela ocupando $2 \mathrm{~m}^{2}$. As estruturas para captação de água foram preparadas após aração na camada de 0 a 30 $\mathrm{cm}$, com uso de uma enxada, quando se confeccionou os camalhões em uma altura de $40 \mathrm{~cm}$, o solo utilizado foi proveniente da abertura dos sulcos, que intercalaram os camalhões espaçados a $1 \mathrm{~m}$ distância um dos outros. As bacias foram preparadas com formato quadrada, com uma área de $1 \mathrm{~m}^{2}$ cada, para formação das bordas puxou-se solo do centro da bacia. Com a confecção das estruturas para captação de água, procedeu-se a distribuição do esterco na linha de plantio conforme as quantidades estudadas, incorporando-os a uma profundidade de $20 \mathrm{~cm}$, após estes procedimentos conservou-se a área em pousio por trinta dias. 
Tabela 2. Características físico-químicas do esterco bovino. Pombal, PB, 2012

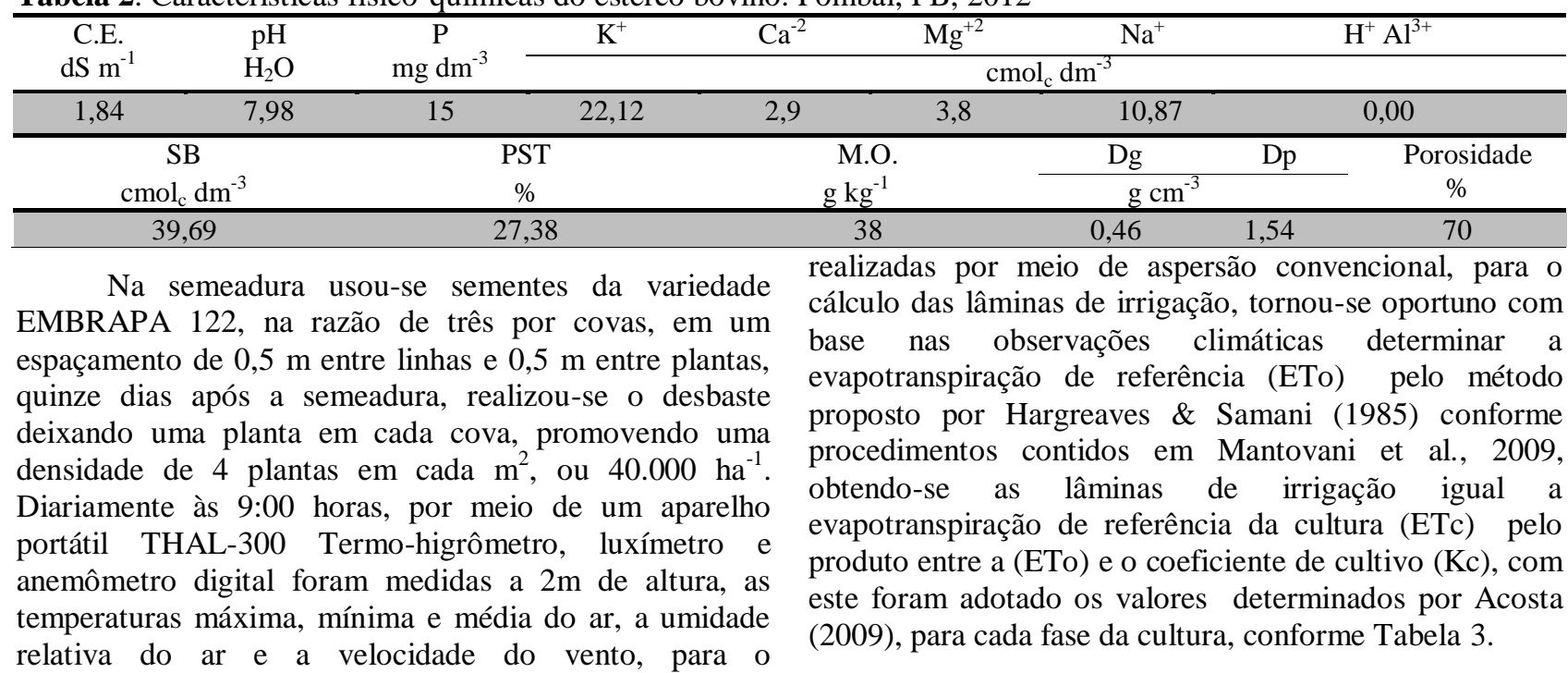
monitoramento das precipitações foi instalado um pluviômetro a $2 \mathrm{~m}$ de altura na área. As irrigações foram

Tabela 3: Coeficiente de cultivo (kc), Evapotranspiração de referência (ETo)(mm), Evapotranspiração real (ETc)(mm), Lâmina de irrigação $(\mathrm{Li})(\mathrm{mm})$, Pluviosidade $(\mathrm{P})(\mathrm{mm})$ e Lâmina Total (Ltotal) $(\mathrm{mm})$ acumuladas para cada fase fenológica e ao longo dos 84 dias de cultivo do girassol, Pombal-PB, 2012

\begin{tabular}{lccccccc}
\hline & $\begin{array}{c}\text { Duração } \\
\text { Fases }\end{array}$ & Kc & ETo & ETc & Li & P & Ltotal \\
\cline { 3 - 8 } & (Dias) & & & & mm & & \\
\hline I - Inicial & 15 & 0,61 & 64,37 & 39,26 & 52,35 & 0 & 52,35 \\
II - D. vegetativo & 25 & 0,87 & 91,81 & 79,87 & 104,46 & 2,03 & 106,49 \\
III - Floração & 20 & 0,83 & 93,56 & 77,66 & 96,92 & 6,62 & 103,54 \\
IV-M. fisiológica & 24 & 0,77 & 79,16 & 60,95 & 63,79 & 17,48 & 81,27 \\
\hline Ciclo & 84 & & 328,9 & 257,74 & 317,52 & 26,14 & 343,65 \\
\hline
\end{tabular}

No monitoramento da umidade do solo foram instalados 60 tensiômetros com manômetros de mercúrio a $20 \mathrm{~cm}$ de profundidade, cada aparelho respondeu por duas parcelas de tratamentos similares, a leituras em centímetros de coluna d'água foi ajustada a equação da

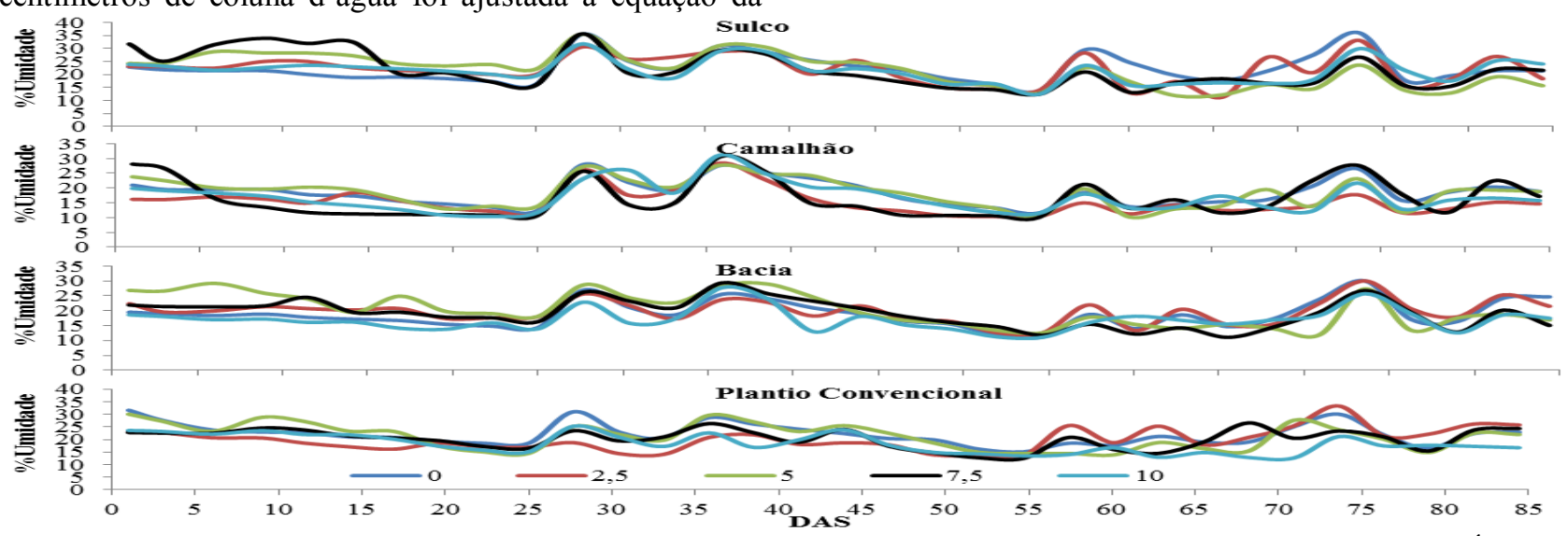

Figura 1. Variabilidade da umidade no solo, para os Níveis de Esterco estudados dentro de cada Técnica de Captação de Água in situ, Sulco, Camalhão, Bacia e Plantio Convencional, Cultura do Girassol, Pombal, PB, 2012

Aos 20, 40, 60 e 80 dias após a semeadura (DAS) digital; Altura de planta (cm), medida do solo até a realizaram-se em quatro plantas por parcela, as seguintes inserção da última folha, fazendo-se uso de fita métrica e, avaliações não destrutivas de crescimento: Diâmetro de pela contagem, determinou-se o número de folhas. A área caule $(\mathrm{mm})$, ao nível do solo, com uso de um paquímetro foliar foi determinada aos 84 DAS pela relação massa de 
uma área conhecida (área de um disco) e massa seca total das folhas, segundo recomendações contidas em Bennicasa et al., (2003). Descrita abaixo, pela seguinte equação 1:

$$
\mathrm{AFP}=\frac{\mathrm{Ad}(\mathrm{MsF}+\mathrm{Msd})}{\mathrm{Msd}}
$$

Em que: $\mathrm{AFP}=$ área foliar da planta $\left(\mathrm{m}^{2}\right) ; \mathrm{Ad}=$ área do $\operatorname{disco}\left(\mathrm{m}^{2}\right) ; \mathrm{Msd}=$ massa seca do disco $(\mathrm{g}) ; \mathrm{MsF}=$ massa seca da folhas $(\mathrm{g})$

De posse dos dados da área foliar por planta, obteve-se, também, o índice de área foliar em função da área ocupada pela planta. Para o cálculo do índice de área foliar foi empregada a equação 2 .

$$
I A F=A P F *(E p * E l)^{-1} \mathrm{~m}^{2} \mathrm{~m}^{-2}(\text { Eq. 2) }
$$

Em que: $\mathrm{IAF}=$ índice de área foliar $\left(\mathrm{m}^{2} \mathrm{~m}^{-2}\right) ; \mathrm{E}_{\mathrm{p}}=$ espaçamento entre plantas $(\mathrm{m}) ; \mathrm{E}_{\mathrm{l}}=$ espaçamento entre linhas de plantio $(\mathrm{m})$.

Os dados obtidos foram submetidos às análises de variâncias, em caso de efeito significativo em função das técnicas, procedeu-se o teste de Tukey e, para o fator esterco e interações as regressões polinomiais (linear e quadrática), com base em metodologia contida em (FERREIRA, 2000).

\section{RESULTADOS E DISCUSSÃO}

Para a variável altura de planta verificou-se efeito significativo das técnicas nas três primeiras observações e o esterco em todas as vezes que foram avaliadas, no entanto observa-se efeito da interação das técnicas de captação de água in situ com as doses de esterco analisado pelo teste $\mathrm{F}(\mathrm{p}<0,01)$, em todos os períodos estudados aos 20, 40, 60 e 80 dias após a semeadura, indicando dependência entre os fatores para com o desenvolvimento desta variável. Esses resultados diferem dos observados por Laime (2012), ao avaliar o crescimento de plantas de pinhão manso em um sistema de captação de agua in situ, não se verificando efeitos das técnicas em estudo, porém o autor fez o estudo em condições totais de sequeiro sem o uso da irrigação suplementar e esterco, diferenciando com o manejo e tratamentos adotados na presente pesquisa. Por outro lado, Leite et al., (2012) observaram que técnicas de captação de água promovem comportamento diferenciado na altura nas plantas de girassol, Wanderley et al., (2012) sorgo sacarino e Barreto et al., (2102) na cultura da fava, em experimentos realizados sob condições de sequeiro no semiárido paraibano.

Com uma análise detalhada nas alterações de altura de planta em função dos efeitos do esterco para com as técnicas de captação (Figura 2), o desdobramento indicou comportamentos diferenciados entre as técnicas com efeitos significativos nas quatro épocas estudadas. Verifica-se, nos sulcos e camalhões (Figura 2 A, B) e em todas as avaliações, que as plantas cresceram em altura de forma linearmente positiva, em função do aumento da quantidade de esterco no solo. As plantas que cresceram nas bacias e preparo do solo convencional em todas as épocas de avaliação, o modelo polinomial de $2^{\circ}$ grau foi à equação mais adequada para as médias obtidas em função dessas técnicas quando relacionadas as quantidade de esterco (Figura 2 C, D). Nobre et al., (2010) avaliando o efeito da adubação orgânica (esterco bovino) sobre esta mesma cultivar em estudo, constataram efeito quadrático dos níveis de esterco para com a altura das plantas. Oliveira et al., (2009) mediante estudos, testando fontes e quantidades de esterco na cultura da mamoneira, sugerem que altas concentrações de esterco promove desequilíbrio nutricional no solo e, em consequência, redução no desenvolvimento e produção final da cultura.

$\mathrm{Na}$ primeira avaliação, aos $20 \mathrm{DAS}$, as plantas cultivadas nas bacias apresentaram o menor desempenho crescendo até $26,7 \mathrm{~cm}$ em função da dose máxima estimada em $3,68 \mathrm{~L} \mathrm{~m}^{-2}$, porém nesta ocasião as demais técnicas pouco diferiram entre si, aos 40 DAS as plantas cultivadas nos camalhões começaram a ostentar uma superioridade em virtude da maior dose de esterco, com $85 \mathrm{~cm}$ de altura, no entanto, as bacias se configuravam ainda mais como a técnica de menor desempenho seguido dos tratamentos plantio convencional. Estes resultados se mantiveram aos 60 DAS, mas as plantas dos sulcos se igualando um pouco às cultivadas nos camalhões, e também os resultados obtidos para as bacias nesta época, ficaram próximos ao sistema convencional de cultivo, porém ainda observando a superioridade da combinação camalhões e a quantidade de esterco em $10 \mathrm{~L} \mathrm{~m}^{-2}$, em relação aos demais tratamentos.

Por ocasião da última avaliação, aos 80 DAS, os maiores valores em altura de plantas foi observado nos camalhões com $125 \mathrm{~cm}$ em função da dose máxima de esterco testado, seguida das plantas cultivadas nos sulcos, com as plantas atingindo alturas de $119,13 \mathrm{~cm}$, a altura máxima verificada aos 80 DAS nas plantas cultivadas nas bacias foi de $117 \mathrm{~cm}$, proveniente da dose ótima estimada em $6,11 \mathrm{~L} \mathrm{~m}^{-2}$ de esterco apresentando decréscimo quando a quantidade de esterco no solo excede este valor, observa-se o mesmo para as plantas cultivadas em solo sob preparo convencional, onde a dose de esterco de melhor desempenho foi de $5,68 \mathrm{~L} \mathrm{~m}^{-2}$, proporcionando uma altura final de $116,4 \mathrm{~cm}$, resultados bastantes próximos aos observados nas bacias. De forma detalhada, os dados obtidos nos presente trabalho divergem dos encontrados por Leite et al., (2012), que observaram os maiores valores em altura nas plantas que cresceram na linha de plantio das bacias. Conforme Barreto et al., (2102), as técnicas de captação de água tipo camalhão promoveram maior crescimento em altura na cultura da fava cultivado no semiárido paraibano. Os valores encontrados na presente pesquisa são inferiores aos observados por Smiderle (2002), ao estudarem a mesma cultivar da presente pesquisa, constatando plantas com altura média de $150 \mathrm{~cm}$. Nobre et al., (2010) estudando esta mesma variedade de girassol sob níveis irrigação com efluente doméstico e doses de adubo 
orgânico, afirmam ter identificado altura máxima de $159,8 \mathrm{~cm}$ em função de $120 \%$ da necessidade hídrica da cultura.

Todavia, em seus estudos Uchôa et al., (2011) comparando três cultivares de girassol (Agrobel 960, Agrobel 967 e Embrapa 122/V2000) e cinco níveis de adubação potássica, verificaram que a cultivar Embrapa 122/V2000, apresentou o menor crescimento com $126 \mathrm{~cm}$ de altura de planta, resultados próximos aos apresentados na presente pesquisa, resultante da combinação entre camalhão e a quantidade de esterco de $10 \quad \mathrm{~L} \mathrm{~m}^{-2}$
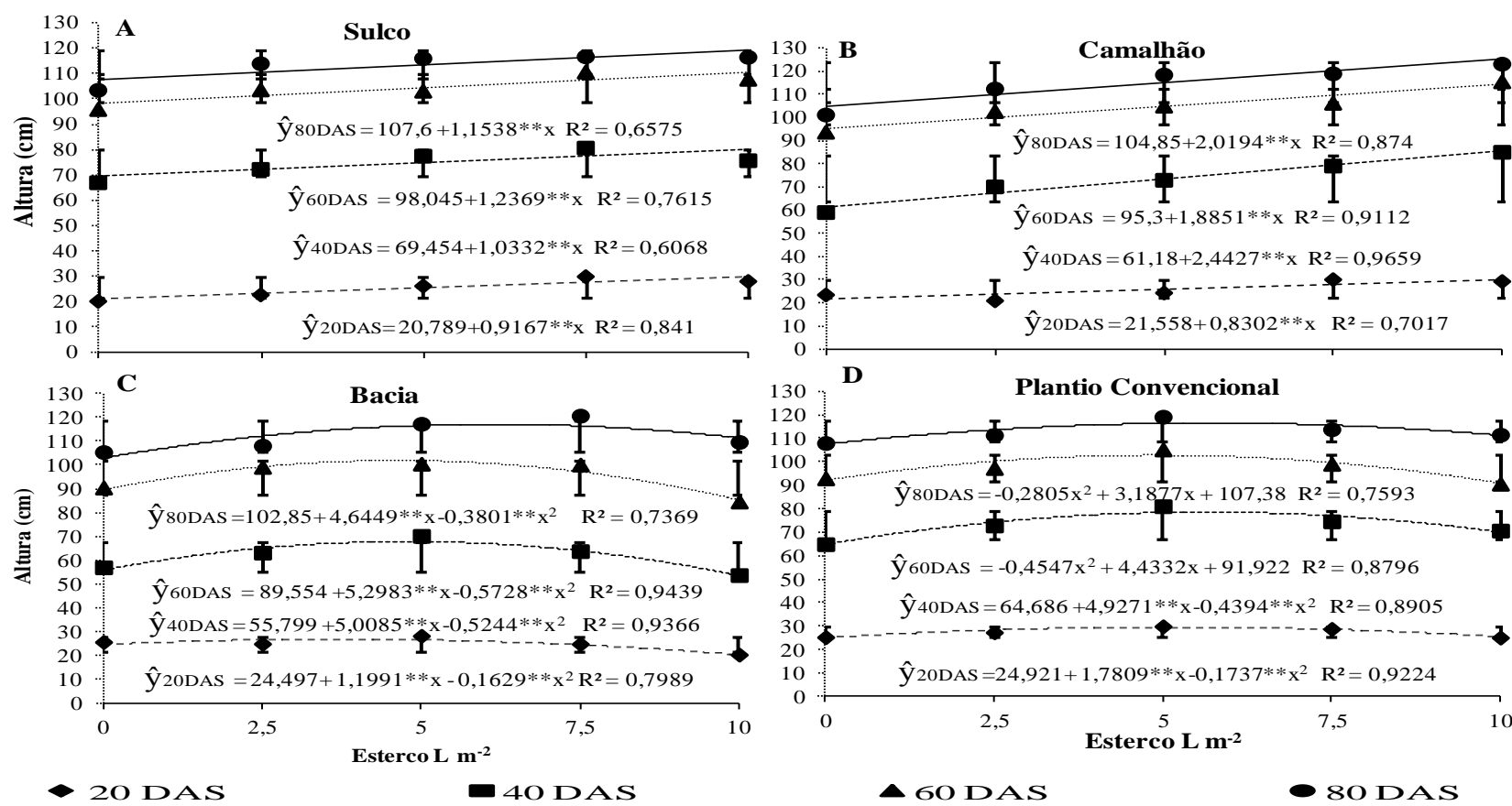

Figura 2. Análise de Regressão (Linear e quadrática) para a variável Altura de Planta (Alt.) (cm), após o desdobramento aos 20, 40, 60 e 80DAS, para os Níveis de Esterco (adubação orgânica) estudados dentro de cada Técnica de Captação de Água in situ, Sulco, (A) Camalhão(B), Bacia (C) e Plantio Convencional(D), Pombal, PB, 2012

Verifica-se, na Figura 3 o efeito significativo $(p<0,01)$ das doses de esterco dentro de cada técnica em todas as combinações entre os fatores para todas as épocas em que o diâmetro de caule foi mensurado, as plantas dos sulcos e camalhões aumentaram de forma linear com o aumento das quantidades de esterco no solo (Figura $3 \mathrm{~A}, \mathrm{~B}$ ), da mesma forma em que ocorreu para a variável altura de planta nas bacias e plantio convencional, o diâmetro de caule aumentou até certa quantidade de esterco e depois diminui com doses mais elevadas, ajustando-se os dados à regressão do tipo quadrática nas épocas em que foi avaliado o diâmetro de caule (Figura 3 C, D). Segundo Oliveira et al., (2009) plantas obtidas com esterco bovino ou com esterco caprino apresentam desenvolvimento similar. Resultados semelhantes foram reportados por Oliveira Júnior et al., (2009) ao estudarem o desenvolvimento de mudas de moringa (Moringa oleífera Lam.) sob diferentes fontes de matéria orgânica.

O crescimento do caule das plantas em diâmetro ocorreu de forma contínua ao longo de todas as avaliações, conforme o tipo de tratamento estabelecido. Ao longo dos períodos avaliados pode-se constatar que o tratamento no qual não foi usada técnica de captação, foi o mais prejudicado, da primeira à última avaliação, corroborando com os resultados obtidos por Laime
(2012), ao observar o desenvolvimento caulinar de plantas de pinhão manso cultivado em sistema de captação de água da chuva.

As plantas cultivadas nos camalhões sempre foram superiores às demais técnicas em todas as épocas que foram avaliadas, apresentaram média de 8,94, 12,59, $15,25 \mathrm{~mm}$, respectivamente aos 20, 40, 60DAS. Na última avaliação, aos 80 DAS, os camalhões se mostraram ser a técnica de melhor aproveitamento no aumento do caule do girassol quando adubado com a dose máxima de esterco bovino em estudo, chegando a 17,76 ( $\mathrm{mm}$ ) de diâmetro de caule, incrementando $15 \%$ em relação aos resultados sem esterco nesta técnica, bem próximo, como foi observado aos 20 DAS, já onde não se fez uso de técnica essa margem caiu para $11 \%$, o desempenho dos sulcos de cultivo foi o de maior aproximação ao camalhão, como observado para altura de planta, durante todas as avaliações as bacias se configuraram como a terceira técnica com as maiores médias obtidas pelas quantidades de esterco entre 5 e $6 \mathrm{Lm}^{-2}$. Contudo, Smiderle (2002) obteve valores em média de $22,1 \mathrm{~mm}$ de caule para esta mesma cultivar, porém se ressalta que o estudo foi realizado na Embrapa Roraima, condições edafoclimáticas diferentes da presente pesquisa, apesar disto, em estudos realizados na cultura do girassol cultivar Multissol submetido a diferentes lâminas de esgoto doméstico 
tratado e água de poço freático e adubado com diferentes doses de nitrogênio, se observaram valores entre 13,3 e 15,23 mm de diâmetro caulinar (FREITAS et al., 2012).

Segundo Jesus et al., (2011) estudando manejo da adubação orgânica no desempenho agronômico do girassol no sertão paraibano, as plantas apresentaram valores médios de $17 \mathrm{~mm}$, para os autores espessura do diâmetro caulinar permite um adensamento maior da cultura e evita o tombamento ou quebra do caule pela ação das chuvas, ventos e animais, respectivamente, favorecendo um aumento na produtividade.
Para Biscaro et al., (2008) elevados diâmetros do caule no girassol constituem uma característica considerada desejável em virtude de conferir à cultura, menor vulnerabilidade ao acamamento e por favorecer a execução de práticas de manejo e tratos culturais. $\mathrm{O}$ processo de crescimento dos caules é menos estudado, mas, provavelmente, afetado pelas mesmas forças que limitam o crescimento foliar durante o estresse (TAIZ; ZEIGER, 2006).
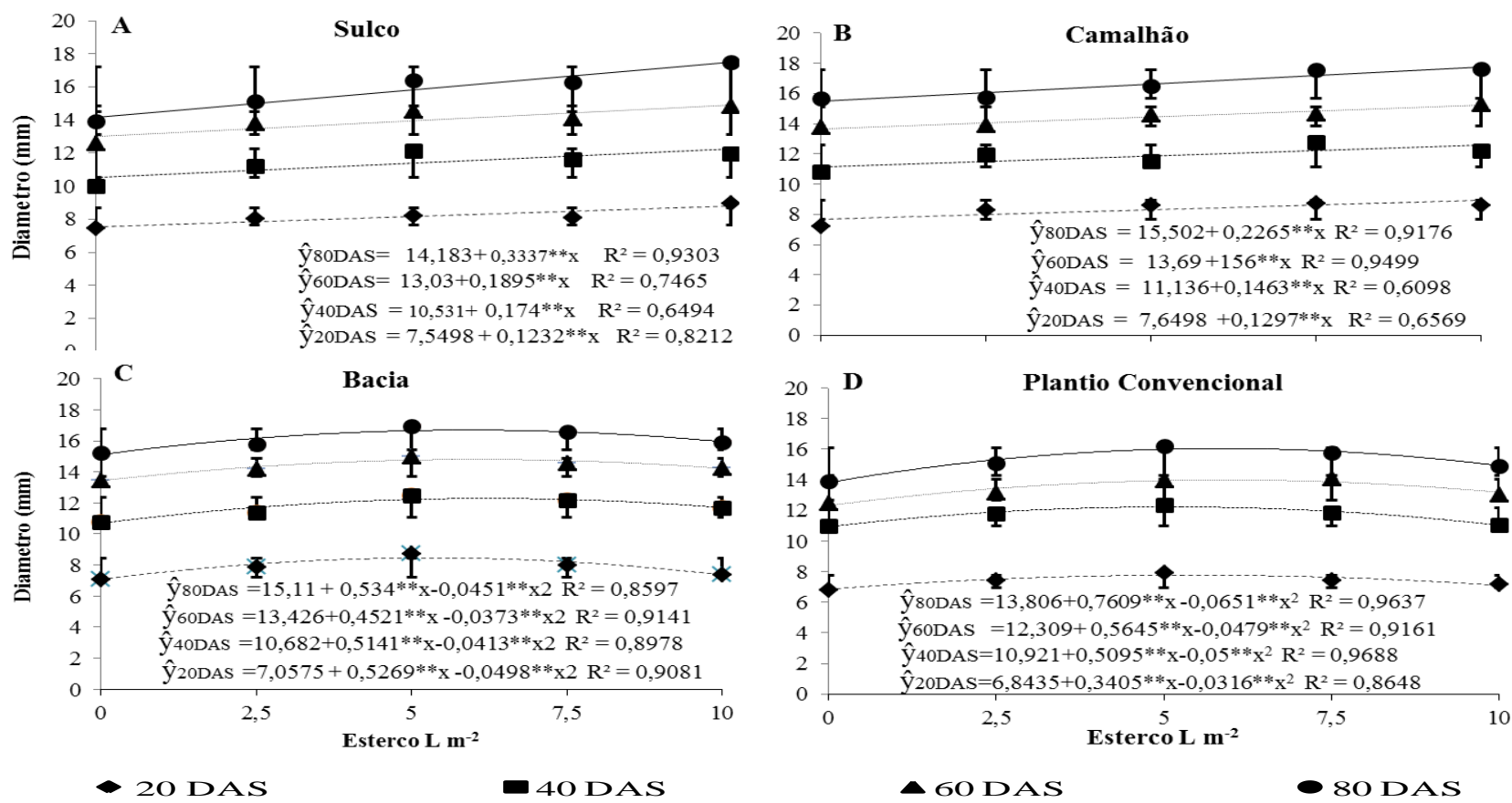

Figura 3. Análise de Regressão (Linear e quadrática) para a variável Diâmetro de Caule (Diam) (mm), após o desdobramento aos 20 , 40, 60 e 80DAS , para os Níveis de Esterco (adubação orgânica) estudados dentro de cada Técnica de Captação de Água in situ, Sulco, (A) Camalhão(B), Bacia (C) e Plantio Convencional(D), Pombal, PB, 2012

As técnicas de captação de água e adubação orgânica exerceram efeitos significativos em nível de $(\mathrm{p}<0,01)$ de forma isolada, no número de folhas, em todas as épocas em que foram avaliadas, com exceção aos 40 DAS cujas técnicas demonstraram nível de significância em $(\mathrm{P}<0,05)$, divergindo dos resultados obtidos por Leite et al., (2012) que avaliando técnicas de captação água, observaram não haver efeito em função desse tratamentos sobre a variável número de folhas do girassol, variedade Hélio 250,cultivada no semiárido paraibano, embora a interação também proporcionou efeito significativo em todas as avalições em nível de $(\mathrm{p}<0,01)$, esses resultados são bastante semelhantes aos observados para as variáveis, altura de plante e diâmetro de caule, já apresentados.

Os valores de número de folhas pela combinação do esterco dentro dos sulcos só apenas aos 20 DAS houve efeito significativo da interação pelo desdobramento das quantidades de esterco aplicado nos sulcos (Figura 4 A), no entanto, nos camalhões, ocorreu efeito significativo da interação nas três últimas avalições (figura 4 B).

Apesar de não ser verificada diferença significativa da interação em todos os momentos em que foram observados, os maiores valores das plantas cultivadas nos sulcos e camalhões, ocorreram em função da maior quantidade de esterco, ou seja, ocorreu aumento linearmente positivo dos números de folhas ao aumento de esterco nessas técnicas (Figura 4 A, B).

Em termos de desempenho aos 20 DAS, o número de folhas foi maior onde não foram usadas técnicas, com aproximadamente 11 folhas, em média, nas plantas cultivadas com uma dose máxima estimada em 4,2 $\mathrm{L} \mathrm{m}^{-2}$ de esterco na linha de plantio, sendo o sulco a técnica em que as plantas se apresentaram com menor número de folhas acima de $3 \mathrm{~cm}$ de comprimento nesta avaliação. No entanto, a partir da segunda avaliação (40 DAS), as plantas cultivadas na linha de plantio dos camalhões onde se aplicou a maior quantidade de esterco, começaram a se mostrar superiores com média de 20 folhas por planta, o que representou aumento de $25 \%$ com relação às plantas 
que não receberam esterco no próprio camalhão, nas duas avaliações subsequentes (60 e 80 DAS) quadro que se estabilizou para os $18 \%$ de incremento.

Contudo, ao comparar os maiores valores encontrados nos camalhões que foi em média 25 folhas, com o máximo das demais técnicas, verificou-se que as plantas cultivadas nos sulcos foram as mais desfavorecidas em todas as avaliações, porém nas plantas com maior número de folhas nesta técnica observou-se, pela dose de $10 \mathrm{~L} \mathrm{~m}^{-2}$, chegando aos 80 DAS com média de 21 folhas, em torno de $18 \%$ a menos que as plantas dos camalhões, mesmo assim, não diferindo estatisticamente dos melhores resultados encontrados nas bacias, em que nas quatros avalições os maiores números de folhas foram obtidos pelas quantidades de esterco entre as faixa de 5,2 a $5,6 \mathrm{~L} \mathrm{~m}^{-2} \mathrm{e}$ no preparo convencional do solo, cujas quantidades de esterco entre 4 e $4,12 \quad \mathrm{~L}^{-2}$ proporcionaram às plantas o maior número de folhas,
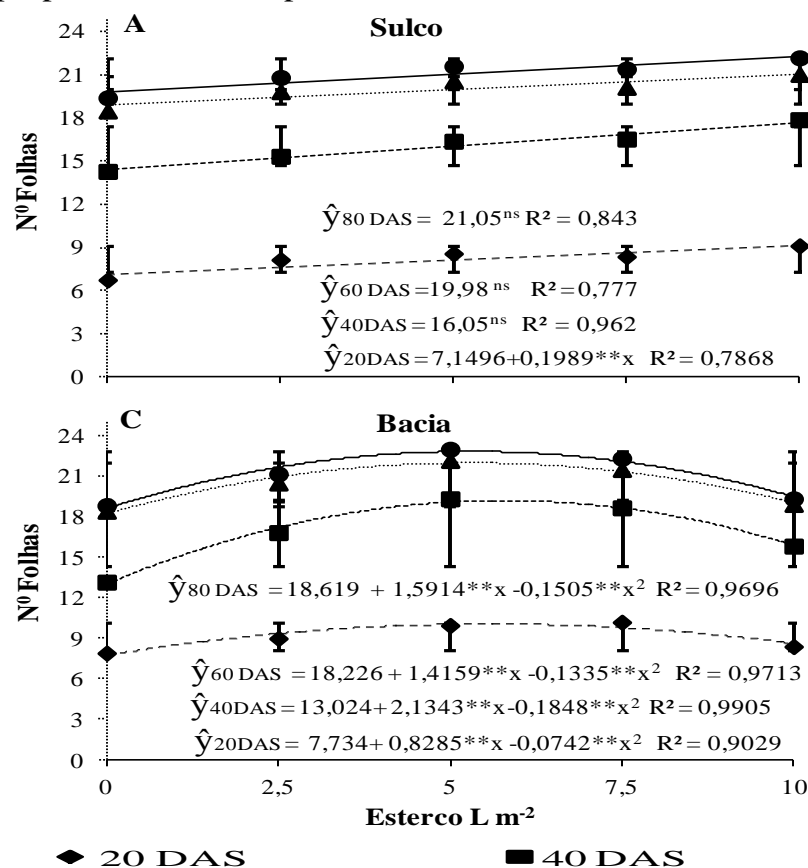

chegando aos 80 DAS em média de 22 unidades foliares por planta para esta técnica.

Bernal (2007), através de estudos realizados na região semiárida do Vale do Jequitinhonha-MG, onde foi testado um sistema de captação de água in situ constatou, em plantas de goiabeira e mangueira, que a técnica camalhão proporcionou às culturas, um número maior de folhas, enquanto para Laime (2012), as técnicas captação de água não resultaram em diferença significativa no número de folhas observadas na cultura do pinhão manso, no entanto o tratamento que mais se destacou foi técnica de plantio em camalhões. De acordo com Dutra et al., (2012), plantas de girassol cultivar Embrapa 122/V-2000, submetidas a maiores teores de água, produzem um número maior de folhas consequentemente, aumenta a área foliar.
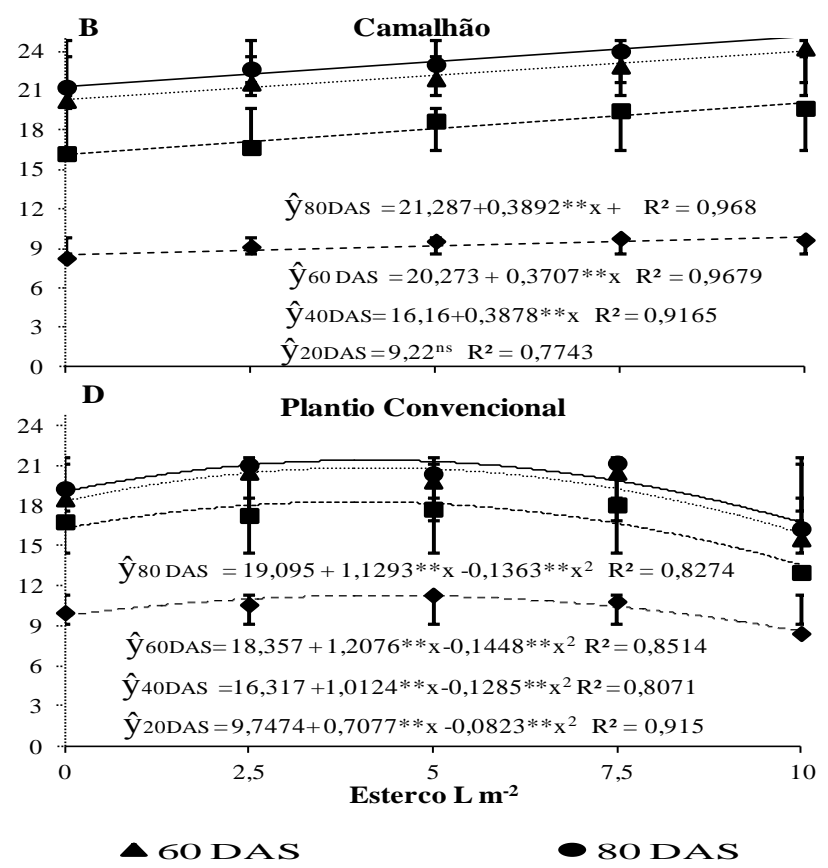

Figura 4. Análise de Regressão (Linear e quadrática) para a variável Número de Folhas ( ${ }^{0}$ Folhas), após o desdobramento aos 20 , 40, 60 e 80 DAS, para os Níveis de Esterco (adubação orgânica) estudados dentro de cada Técnica de Captação de Água in situ, Sulco, (A) Camalhão(B), Bacia (C) e Plantio Convencional (D), Pombal, PB, 2012

A interação técnicas de captação de água e doses de esterco não proporcionou efeito significativo para a variável área foliar (AF) $\left(\mathrm{m}^{2}\right)$ e índice de área foliar (IAF) $\left(\mathrm{m}^{2} \mathrm{~m}^{-2}\right)$, todavia, houve efeito dos fatores isolados em nível de $(\mathrm{p}<0,01)$. Tal fato sugere que o fator água foi o responsável pela diferenciação nos resultados, corroborando com a afirmação de Stone et al., (2001), informando que água é o fator que mais limita o crescimento e a produção das culturas em ambientes áridos e semiáridos, semelhantes aos encontrados no nordeste brasileiro.

A falta de água reduz a pressão de turgor e, como resultado, o fluxo de seiva pelos vasos condutores Taiz \& Zeiger, (2006), fato que tende a diminuir o elongamento celular e, assim, o crescimento e o desenvolvimento das plantas. Conforme Dutra et al., (2012) asseguram que o estresse hídrico provoca mudanças morfológicas e fisiológicas nas culturas, através da redução na expansão celular, redução na área foliar, aumento na abscisão foliar, diminuição da relação entre a biomassa da raiz com a parte aérea, fechamento de estômatos e redução na fotossíntese. Taiz \& Zeiger, (2006) relaciona o ocorrido as modificações que ocorrem nas plantas visando manter seu crescimento e reprodução nesses ambientes limitantes.

De acordo com Larcher (2000) quanto menor a quantidade de água no solo mais negativo deve ser o potencial hídrico, fato que limita o crescimento. Essa escassez de água pode enfraquecer as funções vitais tanto quanto estimular reações adaptativas que capacitem as 
plantas a sobreviverem em períodos prolongados de déficit hídrico.

$\mathrm{Na}$ presente pesquisa a área foliar $(\mathrm{AF})\left(\mathrm{m}^{2}\right)$ e índice de área foliar (IAF) $\left(\mathrm{m}^{2} \mathrm{~m}^{2}\right)$ o melhor resultado foi obtido pela técnica de captação de água tipo camalhão (figura $5 \mathrm{~A}, \mathrm{C}$ ), observa-se também que as demais técnicas não apresentaram diferenças estatísticas.

Os níveis de adubação orgânica também influenciaram de maneira significativa, nessas variáveis, obtendo-se acréscimo com a elevação de uma unidade $1 \mathrm{~L}$ $\mathrm{m}^{-2}$, na ordem de 4,29\%, para ambas as variáveis favorecendo, desta forma o maior crescimento das plantas (Figura $6 \mathrm{~B}, \mathrm{D})$, o que pode estar relacionado com à influência do esterco na conservação da umidade. Esses resultados diferiram dos obtidos por Laime (2012), que observou em plantas de pinhão manso o cultivo em bacias

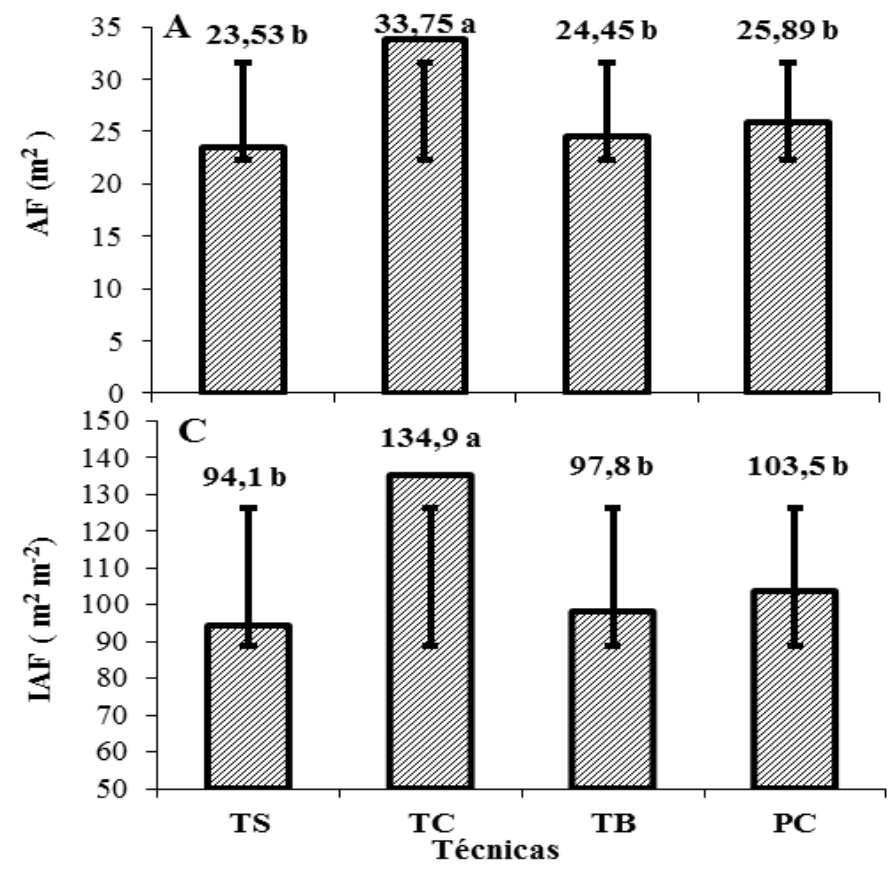

os melhores resultados para área foliar. Para Bernal (2007), que avaliou técnicas de captação de água de chuva na região semiárida do Vale do Jequitinhonha-MG, o plantio em camalhões em nível proporcionou melhor retenção da umidade ao longo do tempo, o que se refletiu em melhor desenvolvimento das plantas e aumento no número das folhas nas culturas de goiabeira e mangueira, que podem ter influência sobre a área foliar.

Vale ressaltar, ainda, que o conhecimento da área foliar da planta possibilita a estimativa da perda de água, uma vez que as folhas são os principais órgãos que participam no processo transpiratório, responsável pela troca gasosa com o ambiente (PEREIRA et al., 1997).

Figura 5. Teste de comparação de média para as variáveis, Área Foliar $(\mathrm{AF})\left(\mathrm{m}^{2}\right)(\mathbf{A})$ e Índice de Área Foliar $(\mathrm{IAF})\left(\mathrm{m}^{2} \mathrm{~m}^{-2}\right)(\mathbf{C})$ aos 84DAS, em função das Técnicas de Captação de Água in situ, e análise de regressão (linear), para a variável Área Foliar (AF) ( ${ }^{2}$ ) (B) e Índice de Ârea Foliar (IAF) $\left(\mathrm{m}^{2} \mathrm{~m}^{-2}\right)$ (D) aos 84 DAS em função dos Níveis de Esterco (adubação orgânica), Pombal, PB, 2012.

\section{CONCLUSÕES}

Ao longo do ciclo o girassol tem o crescimento diferenciado com uso de técnicas para favorecer a captação de água in situ, favorecido pela aplicação de esterco no solo sendo recomendado aplicar a quantidade de $10 \mathrm{Lm}^{-2}$ de esterco na linha de plantio dos camalhões.

O girassol tem a área foliar modificada com uso de técnicas para favorecer a captação de água, e pela aplicação de esterco no solo sendo recomendado aplicar a quantidade de $10 \mathrm{Lm}^{-2}$ de esterco na linha de plantio dos camalhões.

\section{AGRADECIMENTOS}

Os autores agradecem ao $\mathrm{CNPq}$, pelo apoio financeiro ao trabalho e, ao Centro de Ciência e Tecnologia Agroalimentar da UFCG campus de Pombal-PB pelo apoio na realização dos procedimentos de campo e laboratorial necessários na concretização deste trabalho.

\section{LITERATURA CITADA}

ACOSTA, J. F. Consumo hídrico da cultura do girassol irrigada na região da Chapada do Apodi - RN: Campina Grande, 2009. 56p. Dissertação (Mestrado em Meteorologia) - Universidade Federal de Campina Grande. Centro de Tecnologia e Recurso Naturais, UFCG 
BARRETO, C. F.; BRITO, M. E. B.; FERNANDES, P. D.; LEITE, D. T.; WANDERLEY, J. A. C.; ALVINO, F. C. Crescimento da fava cultivado em sistema de captação de água no semiárido da paraíba. Anais. In: IV WINOTEC. Fortaleza-CE, 2012.

BENINCASA, M.M.P. Análise de crescimento de plantas. Jaboticabal: FUNESP, 2003. 41p.

BERNAL, N. A. H. Avaliação de técnicas de captação de água de chuva para recuperação ambiental na região semi-árida do Vale do Jequitinhonha. Belo Horizonte, 2007. 202p (Tese de Doutorado) - UFMG

BISCARO, G. A.; MACHADO, J. R.; TOSTA, M. da S.; MENDONÇA, V.; SORATTO, R. P.; CARVALHO, L. A. de. Adubação nitrogenada em cobertura no girassol irrigado nas condições de Cassilândia- MS. Revista Ciência e Agrotecnologia, V.32, p.1366-1373, 2008.

DUTRA, C. C.; PRADO, E. A. F.; PAIM, L. R.; SCALON, S.P. Q. Desenvolvimento de plantas de girassol sob diferentes condições de fornecimento de água. Semina. V. 33, n.1, p. 2657-2668, 2012

FERREIRA, P. V. Estatística experimental aplicada à agronomia. 2ed. Revisada e ampliada. Maceió: UFAL/EDUFAL/FUNDEPES, 2000. 437p.

FREITAS, C. A. S.; SILVA, A. R. A.; BEZERRA, F. M. L.; ANDRADE, R. R.; MOTA, F. S. B.; AQUINO, B. F. Crescimento da cultura do girassol irrigado com diferentes tipos de água e adubação nitrogenada. Revista Brasileira de Engenharia Agrícola e Ambiental. V.16, n.10, p.1031-1039, 2012

GOMES, E. P.; ÁVILA, M. R.; RICKLI, M. E. ; PETRI, F.; FEDRI, G. Desenvolvimento e produtividade do girassol sob lâminas de irrigação em semeadura direta na região do arenito caiuá, estado do paraná. Irriga. V. 15, n. 4, p. 373-385, 2010

JESUS, D. S.; PAIXÃO, C. L.D.; SANTOS, G. L.; PEREIRA, P. P. A.; SOUZA, O. S. Q.; AZEVEDO NETO, A. D. Crescimento e teores de NPK em genótipos de girassol sob estresse por alumínio. ANAIS: $19^{\mathrm{a}}$ Reunião Nacional de Pesquisa de Girassol: $7^{\mathbf{0}}$ Simpósio Nacional sobre a Cultura do Girassol - Aracaju/SE, p101 -104, 2011

LAIME, E. M. O. Sistemas de captação de água in situ em função do crescimento e produção do pinhãomanso: Campina Grande, 2012. 65p, Dissertação de Mestrado, Engenharia Agrícola (Irrigação e Drenagem), UFCG.
LARCHER, W. Ecofisiologia Vegetal. Tradução: Prado, C. H. B. A. Ed. Rima, São Carlos, 2000.

LEITE, D. T.; BRITO, M. E. B.; FERNANDES, P. D.; BARRETO, C. F.; WANDERLEY,J. A. C.; ALVINO, F. C. Crescimento do girassol cultivado sob técnicas de captação de água da chuva in situ. Anais. In: IV WINOTEC. Fortaleza-CE, 2012.

MANTOVANI, E. C.; BERNARDO, S,; PALARETTI, L. F. Irrigação: princípios e métodos, 2ed, atual e ampliada, Viçosa, MG: UFV, 355 p, 2009

NEUMANN, M.; OLIBONI, R.; OLIVEIRA, M. R.; GÓRSKI, S. C.; FARIA, M.V.; UENO, R. K.; MARAFON, F. Girassol (Helianthus annuus L.) para produção de silagem de planta inteira. Revista Pesquisa Aplicada \& Agrotecnologia. V. 2, n.3, p181-190. 2009

NOBRE, R. G.; GHEYI, H. R.; SOARES, F. A. L.; ANDRADE, L. O.; NASCIMENTO, E. C. S. Produção do girassol sob diferentes lâminas com efluentes domésticos e adubação orgânica. Revista Brasileira de Engenharia Agrícola e Ambiental. V.14, n.7, p.747-754, 2010

OLIVEIRA JÚNIOR, S.; SOUTO, J. S.; SANTOS, R. V.; SOUTO, P. C.; MAIOR JÚNIOR, S. G. S. Adubação com diferentes estercos no cultivo de moringa (Moringa oleifera Lam.). Revista Verde. V.4, n.1, p.125 - 134, 2009

OLIVEIRA, F. A.; OLIVEIRA FILHO, A. F.; MEDEIROS, J.F.; ALMEIDA JÚNIOR, A. B.; LINHARES, P. C.F. Desenvolvimento inicial da mamoneira sob diferentes fontes e doses de matéria orgânica. Revista Caatinga. V. 22, n.1, p.206-211, 2009

OLIVEIRA, J. T. L.; CHAVES, L.H. G.; CAMPOS, V.B.; SANTOS JÚNIOR, J. A.; GUEDES FILHO, D. H. Fitomassa de girassol cultivado sob adubação nitrogenada e níveis de água disponível no solo. Revista Brasileira de Agricultura Irrigada. V.6, n. 1, p.23-32, 2012

PEREIRA, A. R.; VILLA NOVA, N. A.; SEDIYAMA, G. C. Evapotranspiração. Fundação de Estudos Agrários Luís de Queiroz, 1997. 183p.

PORTO, E. R.; VIVALLO PINARE, A. G.; WILLIAMS FUENTES, C. O. ; SILVA, A. S.; LOPES, L. H. O. Pequenos Agricultores $\mathrm{V}$ : métodos de execução de sistemas integrados de produção agropecuária (SIP). Petrolina: EMBRAPA, 1990.

RIGON, J. P. G.; MORAES, M. T.; ARNUTI, F.; CHERUBIN, M. R.; TREVISOL, G.; PESSOTTO, P. P.; CAPUANI, S.; SILVA, V. R. Potencial agrícola da utilização de composto orgânico de lixo urbano na cultura do girassol. IV Congresso Brasileiro de Mamona e I 
Simpósio Internacional de Oleaginosas Energéticas, João Pessoa, PB, p 731-735 - 2010

SANTOS JUNIOR, J. A.; GHEYI, H. R.; DIAS, N. S.; SOARES, F. A. L.; NOBRE, R. G. Doses de boro e água residuária na produção do girassol. Revista Ciência Agronômica. V. 42, n. 4, p. 857-864, 2011

SILVA, L. S.; CANELlAS, L. P.; CAMARGO, F. A. O. Fundamentos de matéria orgânica do solo: ecossistemas tropicais e subtropicais. Porto Alegre: Metrópole, 2008. cap.32, p.1.

SMIDERLE, O. J. Potencial de produção de girassol em duas épocas de semeadura em Roraima. Embrapa Roraima. Boletim de Pesquisa e Desenvolvimento. n.2, 16p. 2002.

STONE, L.R.; GOODRUM, D.E.; JAAFAR, M.N.; KHAN, A.K. Rooting Front and Water Depletion Depths in Grain Sorghum and Sunflower. Agronomy Journal 93:1105-1110, 2001.

TAIZ, L.; ZEIGER, E. Fisiologia vegetal. Porto Alegre: Artmed Editora, 2006.

UCHÔA, S. C. P. IVANOFF, M. E. A.; ALVES, J. M. A.; SEDIYAMA, T.; MARTINS, S. A. Adubação de potássio em cobertura nos componentes de produção de cultivares de girassol. Revista Ciência Agronômica, v. 42, n. 1, p. $8-15,2011$

WANDERLEY, J. A. C.; BRITO, M. E. B.; FERNANDES, P. D.; BARRETO, C. F.; LEITE, D. T.; ALVINO, F. C. Crescimento do sorgo sacarino cultivado sob técnicas de captação de água de chuva. Anais. In: IV WINOTEC. Fortaleza-CE, 2012. 